\title{
Subtotal ureteral substitution with ileum for patients with multiple ureteral stenosis
}

\author{
Francesco Porpiglia ${ }^{1}$, Enrico Checcucci ${ }^{1}$, Federico Piramide ${ }^{1}$, Daniele Amparore ${ }^{1}$, Cristian Fiori ${ }^{1}$, \\ Ashok Hemal ${ }^{2}$ \\ ${ }^{1}$ Division of Urology, Department of Oncology, School of Medicine, University of Turin, San Luigi Hospital, Orbassano, Italy; ${ }^{2}$ Department of \\ Urology, Wake Forest School of Medicine, Winston-Salem, NC, USA \\ Correspondence to: Prof. Francesco Porpiglia. Division of Urology, Department of Oncology, School of Medicine, University of Turin, San Luigi \\ Hospital, Regione Gonzole 10, 10043 Orbassano, Italy. Email: porpiglia@libero.it.
}

\begin{abstract}
The use of small bowel for ureteral substitution in patients with ureteral stenosis can, nowadays, be safely performed with a laparoscopic or robotic mini-invasive approach. To date, this technique required a complete substitution of the ureter with ileum. In this work we present our robotic intracorporeal subtotal ureteral substitution preserving the distal part of the ureter with the aim to reduce the risk of vescicoureteral reflux. We report the case of a 65 -years old male with a "functional" right single kidney and multiple recurrent stenosis. Our technique seems to be feasible and safe, no intra or postoperative complication were recorded. At 3 months of follow-up the trans-nephrostomic enhanced CT showed a completely opacification of ileal ureter, thus the nephrostomic tube was removed. At 6 and 12 months the patient was asymptomatic and with a level of serum creatinine 1.9 and $1.6 \mathrm{mg} / \mathrm{dL}$, respectively. In conclusion the sub-total ureteral substitution with ileum can be a safety and effective procedure for patients who require a mandatory preservation of homolateral renal function.
\end{abstract}

Keywords: Ureteral reimplantation; ileal ureter, robotics; reconstructive surgery

Submitted Nov 26, 2019. Accepted for publication Dec 24, 2019.

doi: $10.21037 /$ tau.2019.12.32

View this article at: http://dx.doi.org/10.21037/tau.2019.12.32

\section{Introduction}

The use of small bowel for ureteral substitution in patients with ureteral stenosis is already well know and established starting from the first experience in open surgery in 1959 (1). In the last years, with the advent of mini-invasive surgery preliminary experience were published both for laparoscopy and robotics: firstly "hybrid" procedures with open iliac reanastomosis (2), then, in 2014, fully with mini-invasive approach $(3,4)$.

In all these series the ureter was completely substituted with ileum, performing cranial anastomosis between renal pelvis and ileal ureter, and caudal anastomosis between ileal ureter and bladder.

In this paper we present our robotic intracorporeal subtotal ureteral substitution preserving the distal part of the ureter with the aim to reduce the risk of vescico-ureteral reflux.

\section{Materials and methods}

\section{Patient details}

We report the case of a 65-year-old gentleman, with "functional" right single kidney with moderate chronic kidney diseases undergone radiotherapy for Burkitt Lymphoma in early 80's. In the early 2000's he underwent implantable penile prosthesis, with reservoir placed extraperitoneally on the right side. In September 2018, during follow up visits, right hydronephrosis due to $2 \mathrm{~cm}$ lumbar ureteral stenosis was found.

Patients underwent robot-assisted right iliac ureterectomy and end-to-end anastomosis in October 2018. Post-operative course was uneventful, double J stent was removed 4 weeks after surgery. Three months after surgery, follow up US revealed right hydronephrosis. CT showed $1 \mathrm{~cm}$ stenosis at the level of right ureter (Figure 1). The 
A

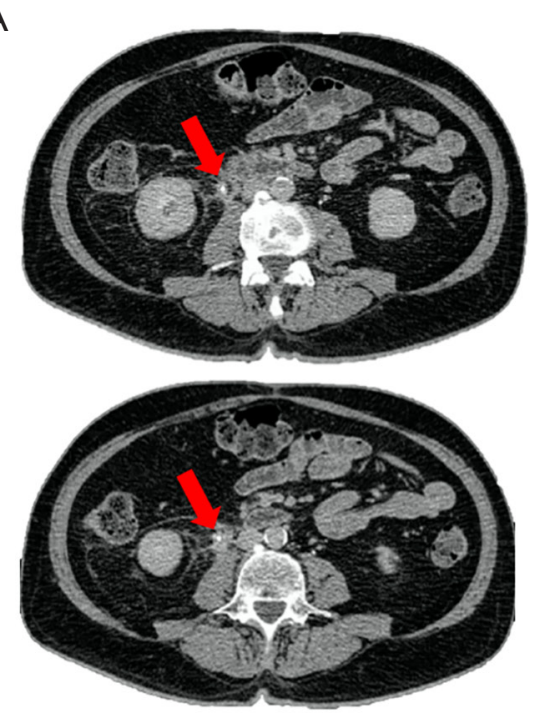

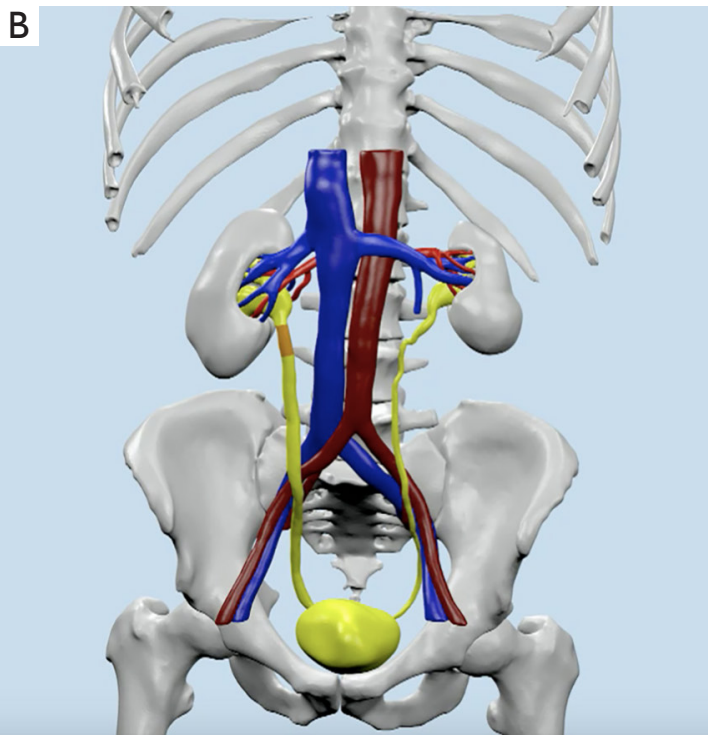

Figure 1 Preoperative CT scan and 3D reconstruction. (A) Three months after surgery the CT scan showed 1 cm stenosis at the level of right ureter; (B) 3D reconstruction simulates the location and length of the stenosis.

serum creatinine was $1.8 \mathrm{~mL} / \mathrm{dL}$. A right double $\mathrm{J}$ stent was placed.

Considering the previously radiotherapy with the subsequent damage of the ureteral tissue and the precociousness of the recidivism of the stenosis, the endoscopic treatment of the stenosis or the segmental urethrectomy with re-anastomosis were excluded.

Moreover, with the aim to avoid damaging the renal function of the single "functional" kidney, a total ureteral substitution, that is related with high risk of reflux, was excluded as well; therefore, a subtotal ureteral substitution was planned. The following surgical technique is explained by accompaniment video (Video 1).

\section{First step: dissection of the lumbar ureter}

The patient was placed in modified flank position initially. Pneumoperitoneum was induced by placing a Veress needle. Camera port was placed on the pararectal line $3-4 \mathrm{~cm}$ above umbilicus, three operative robotic ports were positioned on the same (pararectal) line, $4 \mathrm{~cm}$ one from each other. The $12 \mathrm{~mm}$ assistant port was placed on the midline, just above the umbilicus and $5 \mathrm{~mm}$ ancillary was placed at le level of xyfoid. A $30^{\circ}$ laparoscope, side-down was used (Figure 2).

The colon was dissected medially, the gonadal and cava veins were identified. The ureter was identified, it was extremely adherent within the retroperitoneum tissue, due to fibrosis post radiotherapy. Ureterolysis was extremely challenging, nevertheless the ureter was isolated from uretero-pelvic junction (UPJ) to iliac vessels but it appeared stenotic and avascular in its two proximal thirds (Figure 3).

Due to poor quality of ureteral tissue and the length of stenosis that did not allowed an "end to end anastomosis" the small calibre of gonadal vein that did not allow a RUG technique (5) and inadequate length of appendix we were forced to choose an ileal-ureteral substitution.

\section{Second surgical step: dissection of distal ureter + bowel isolation and reestablishment of bowel continuity, uretero- ileal anastomosis}

It was necessary to undock the robot and place the patient in lithotomic position. Six Ports were placed in a fan, RARP like, shape (Figure 4).

The peritoneum was incised, the distal ureter was identified and dissected. This part of the ureter appears regular, well vascularized and without stenosis. In order to avoid vescico-uretral reflux and to avoid the handling of the prosthesis' reservoir we opted to preserve the distal part of the ureter. A 20-cm ileal segment was measured and isolated approximately $20 \mathrm{~cm}$ proximal to the ileocecal valve using 


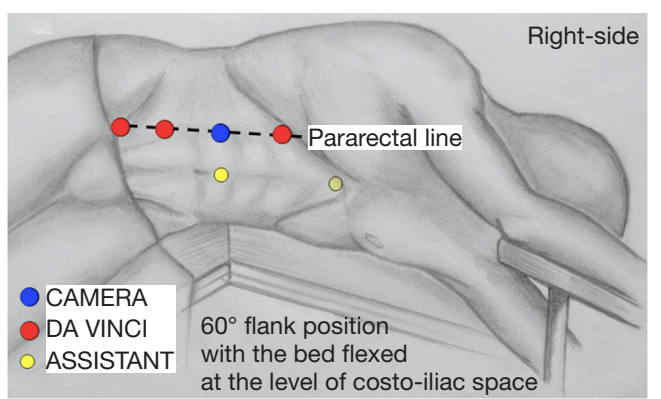

Figure 2 Patient's positioning and trocars' placement for the dissection of the lumbar ureter.

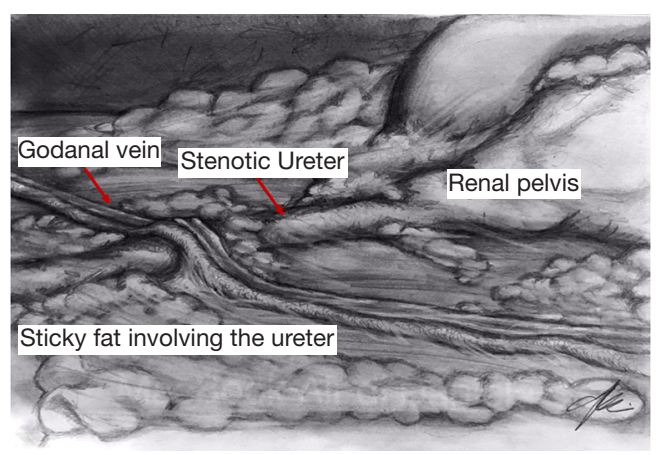

Figure 3 The ureter was identified and isolated and it appeared stenotic and avascular in its two proximal thirds.

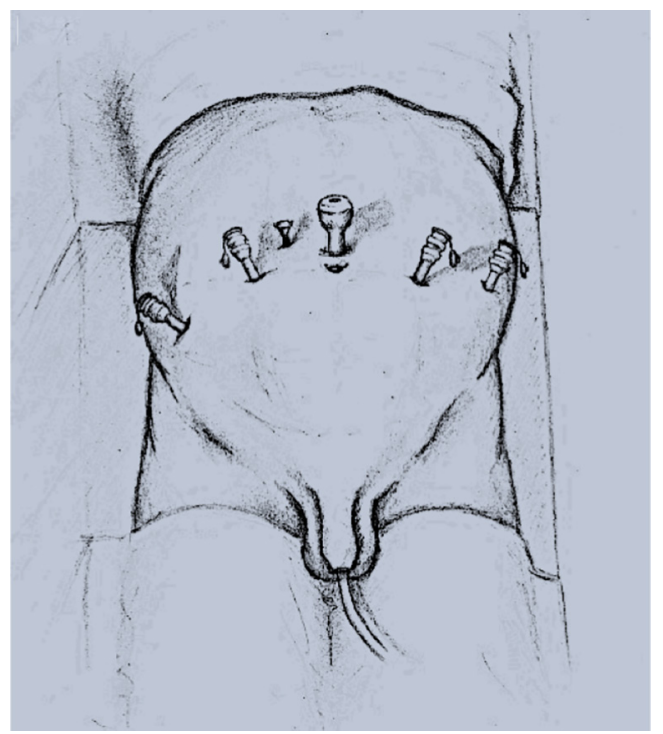

Figure 4 Patient's positioning and trocars' placement for the management of the distal ureter and bowel.

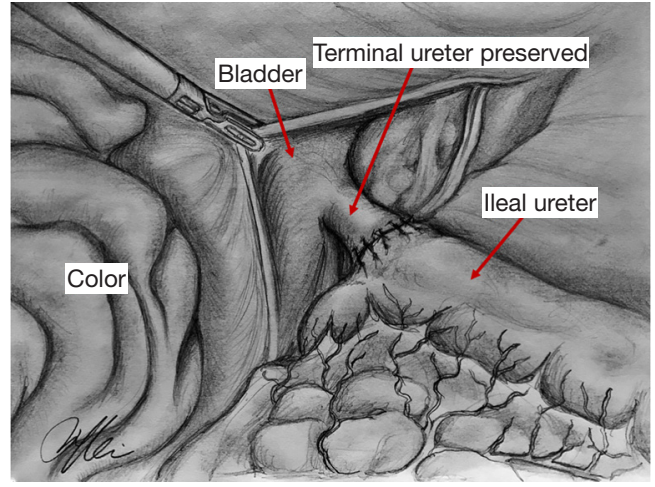

Figure 5 The anastomosis between ileal loop and distal ureter was performed with interrupted $4 \backslash 0$ monofilament stiches.

several Endo-GIA stapler loads (Covidien, Mansfield, USA). Continuity of the bowel was re-established performing a latero-lateral anastomosis by using Endo-GIA stapler again, as we previously described for robotic cystectomy (6). Then the anastomosis between ileal loop and distal ureter was performed with interrupted $4 \backslash 0$ monofilament stiches (Figure 5).

\section{Third step: ileo-pyelic anastomosis}

The daVinci system was undocked and the patient was placed again in flank position. Docking and ports were the same of the first step of the procedure. The ureter was sectioned at the level of UPJ. The posterior plate of ileopyelic anastomosis was performed with a running suture by using $4 \backslash 0$ monofilament suture. A double J stent was placed in a retrograde fashion, finally the anterior plate of ileo-pyelic anastomosis was completed (Figure 6). Both anastomoses were checked by using flexible ureteroscopy.

The haemostasis was controlled, and a drain tube was placed in the periureteral space, moreover, prudentially, a nephrostomic tube was placed.

\section{Results}

Operative time was $4 \mathrm{~h}$, no intraoperative or postoperative complications were recorded. Estimated blood losses were $400 \mathrm{cc}$. The patients were discharged in 10 postoperative day.

At third month of follow-up the trans-nephrostomic 
enhanced computer-tomography showed a completely opacification of ileal ureter; indeed, the nephrostomy was removed (Figure 7). At mild-term of 6 months of followup serum creatinine was $1.9 \mathrm{mg} / \mathrm{dL}$ and the patient was asymptomatic.

\section{Conclusions}

The safety of robotics in ureteral surgery is already well known (7), also for ureteral reconstruction $(8,9)$. However, adoption of minimal invasive techniques for ileal ureteric

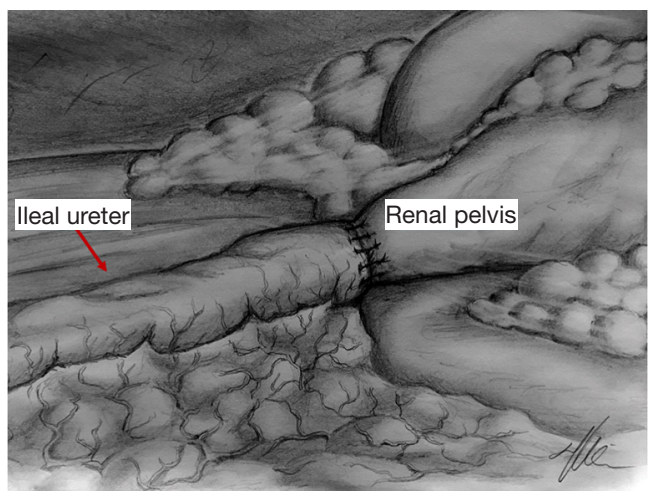

Figure 6 The ileo-pyelic anastomosis was performed with $4 \backslash 0$ monofilament stiches. substitution has been slow and late, presumably because of the complexity of the procedure and the extent of the surgical field. Brandao et al. (3) were the first that report a case of completely intracorporeal robotic ileal ureter in a patient with multiple strictures. The first series of 7 patients who underwent to robotic intracorporeal ileal ureter with 3 months of follow-up was recently published by Ubrig et al. in 2018 (4) showing a complete functional restoration of the upper urinary tract and significant renal recovery.

Notwithstanding the technical and technological innovation, the experiences of robotic ureteral substitution reported in the Literature still remain anecdotical (Table 1) (3,4,10-14).

The novelty of our technique is represented by the fact that for the first time the distal tract of the ureter was maintained, and the caudal anastomosis was performed between the ureter preserved and the tabularised ileum. The rationale of this approach is that with the preservation of the distal part of the ureter the intradetrusorial portion of the ureter was maintained avoiding damaging the natural anti reflux mechanism.

In conclusion, notwithstanding the complexity of this technique, the sub-total ureteral substitution with ileum can be a safety and effective procedure, that can be performed in patient with long life expectancy whom required a preservation of homolateral renal function.
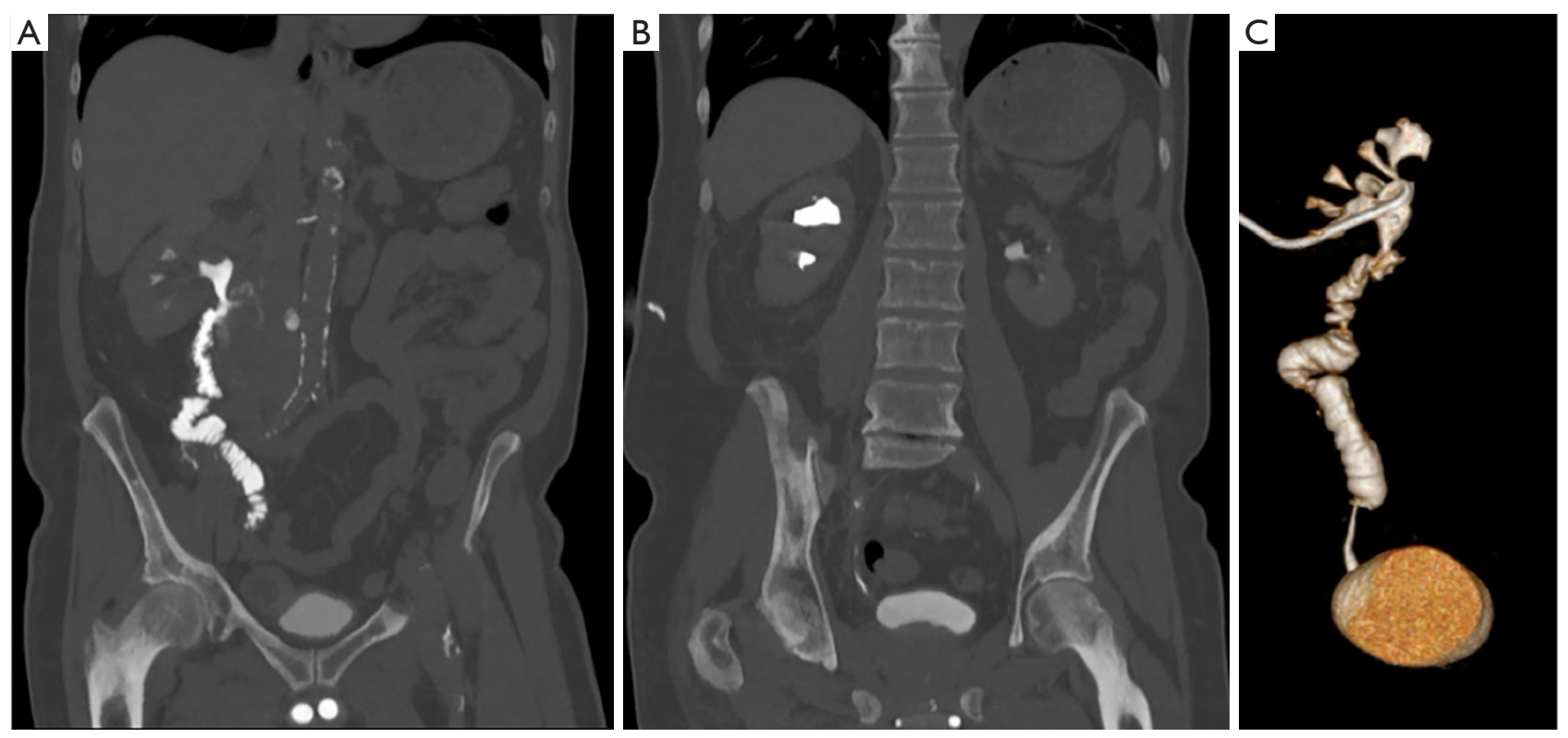

Figure 7 At third month of follow-up the trans-nephrostomic enhanced computer-tomography showed a completely opacification of ileal ureter; indeed the nephrostomy was removed. 


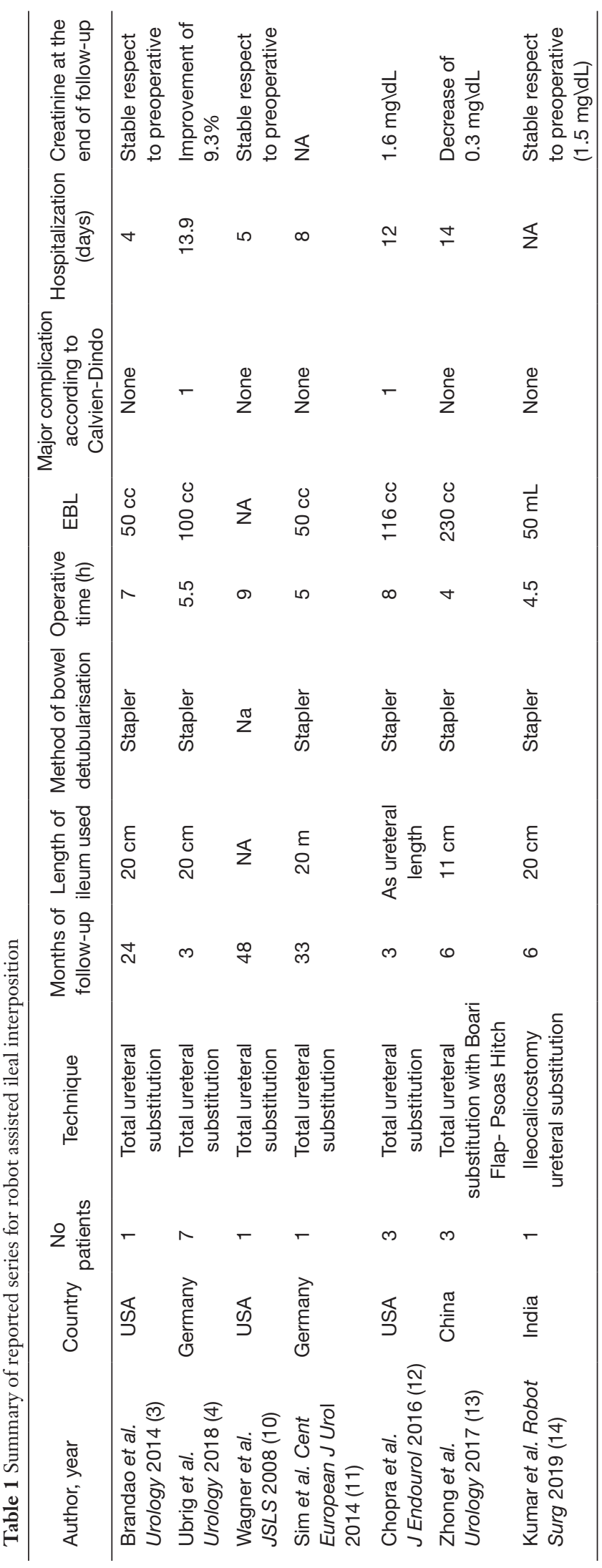

\section{Acknowledgments}

Funding: None.

\section{Footnote}

Provenance and Peer Review: This article was commissioned by the Guest Editor (Ashok K. Hemal) for the series "Robotic-assisted Urologic Surgery" published in Translational Andrology and Urology. The article was sent for external peer review organized by the Guest Editor and the editorial office.

Conflicts of Interest: All authors have completed the ICMJE uniform disclosure form (available at http://dx.doi. org/10.21037/tau.2019.12.32). The series "Robotic-assisted Urologic Surgery" was commissioned by the editorial office without any funding or sponsorship. AH served as the unpaid Guest Editor of the series and serves as the unpaid editorial board member of Translational Andrology and Urology from May 2019 to Apr 2021. The other authors have no other conflicts of interest to declare.

Ethical Statement: The authors are accountable for all aspects of the work in ensuring that questions related to the accuracy or integrity of any part of the work are appropriately investigated and resolved. Written informed consent was obtained from the patient for publication of this manuscript and any accompanying images.

Open Access Statement: This is an Open Access article distributed in accordance with the Creative Commons Attribution-NonCommercial-NoDerivs 4.0 International License (CC BY-NC-ND 4.0), which permits the noncommercial replication and distribution of the article with the strict proviso that no changes or edits are made and the original work is properly cited (including links to both the formal publication through the relevant DOI and the license). See: https://creativecommons.org/licenses/by-nc$\mathrm{nd} / 4.0 \%$.

\section{References}

1. Goodwin WE, Winter CC, Turner RD. Replacement of the ureter by small intestine: clinical application and results of the ileal ureter. J Urol 1959;81:406-18.

2. Gill IS, Savage SJ, Senagore AJ, et al. Laparoscopic ileal ureter. J Urol 2000;163:1199-202. 
3. Brandao LF, Autorino R, Zargar H, et al. Robotic ileal ureter: a completely intracorporeal technique. Urology 2014;83:951-4.

4. Ubrig B, Janusonis J, Paulics L, et al. Functional Outcome of Completely Intracorporeal Robotic Ileal Ureteric Replacement. Urology 2018;114:193-7.

5. Dal Moro F, Macchi V, Porzionato A, et al. RUG technique: replacement of the ureter with gonadal vein. A cadaveric study. Minerva Urol Nefrol 2019;71:85-91.

6. Porpiglia F, Morra I, Mele F, et al. Robot-assisted approach to "Y"- configuration urinary diversion: A stepby-step technique. European Urology Supplements 2018;17:257-8.

7. Buffi NM, Lughezzani G, Hurle R, et al. Robot-assisted Surgery for Benign Ureteral Strictures: Experience and Outcomes from Four Tertiary Care Institutions. Eur Urol 2017;71:945-51.

8. Kolontarev K, Kasyan G, Pushkar D. Robot-assisted laparoscopic ureteral reconstruction: a systematic review of literature. Cent European J Urol 2018;71:221-7.

Cite this article as: Porpiglia F, Checcucci E, Piramide F, Amparore D, Fiori C, Hemal A. Subtotal ureteral substitution with ileum for patients with multiple ureteral stenosis. Transl Androl Urol 2020;9(2):971-976. doi: 10.21037/tau.2019.12.32
9. Tracey AT, Eun DD, Stifelman MD, et al. Robotic-assisted laparoscopic repair of ureteral injury: an evidence-based review of techniques and outcomes. Minerva Urol Nefrol 2018;70:231-41.

10. Wagner JR, Schimpf MO, Cohen JL. Robot-assisted laparoscopic ileal ureter. JSLS 2008;12:306-9.

11. Sim A, Todenhöfer T, Mischinger J, et al. Intracorporeal ileal ureter replacement using laparoscopy and robotics. Cent European J Urol 2014;67:420-3.

12. Chopra S, Metcalfe C, Satkunasivam R, et al. Initial Series of Four-Arm Robotic Completely Intracorporeal Ileal Ureter. J Endourol 2016;30:395-9.

13. Zhong W, Du Y, Yang K, et al. Ileal Ureter Replacement Combined With Boari Flap-Psoas Hitch to Treat Full-Length Ureteral Defects: Technique and Initial Experience. Urology 2017;108:201-6.

14. Kumar S, Chandna A, Khanna A, et al. Robot assisted intra-corporeal ileocalicostomy ureteral substitution for complex uretero-pelvic junction obstruction: a novel and feasible innovation. J Robot Surg 2019;13:589-93. 